\title{
Non-invasive risk stratification of patients with TTR amyloidosis
}

\author{
Katrin A Scherer ${ }^{1 *}$, Fabian aus dem Siepen ${ }^{1}$, Rebekka Kammerer ${ }^{1}$, Stefan E Hardt ${ }^{1}$, Ralf Bauer ${ }^{1}$, Uwe Haberkorn², \\ Arnt $\mathrm{V}$ Kristen ${ }^{1}$ \\ From 16th Annual SCMR Scientific Sessions \\ San Francisco, CA, USA. 31 January - 3 February 2013
}

\section{Background}

Transthyretin (TTR) is the major constituent of severe systemic amyloid diseases with a broad spectrum of genotypes and heterogeneous phenotypes. Data on risk stratification is lacking. We evaluated the impact of different imaging tools for risk assessment in TTR patients.

\section{Methods}

30 patients (21 male, 9 female; median age 69.5 years) with diagnosis of TTR amyloidosis (wild-type $n=13$, hereditary $\mathrm{n}=17$ ) were evaluated by cardiac MRI (CMR; Achieva Intera ${ }^{\circledR}$ Philips Medical Systems, Best, The Netherlands), and ${ }^{99 \mathrm{~m}}$ Technetium-DPD scintigraphy. EDV, ESV, EF and myocardial mass were analyzed on a standard workstation (Philips Viewforum). Longitudinal function was assessed by mitral (MAPSE) and tricuspid (TAPSE) annular plane systolic excursion. Atrial septum thickness was measured on SSFP-4 chamber views. Gadolinium contrast-enhanced CMR (CE-CMR) was assessed semi-quantitatively (absent $=0$, weak $=1$, moderate $=2$, severe $=3$ ) in an AHA modified 16 segment model of the left ventricle as well as for the right/left atrium and right ventricle. Nuclear DPDretention was assessed semi-quantitatively using a region of interest technique by comparison of counts in the heart at 3 hours after injection with whole body counts at 5 min after injection.

\section{Results}

Median troponin T 0.02 [0.004; 0.12] $\mu \mathrm{g} / \mathrm{l}, \mathrm{NT}$-proBNP 1217 [13; 6977] $\mathrm{ng} / \mathrm{l}$, and MDRD 76 [43; 134] $\mathrm{ml} /$ $\left(\min ^{*} 1,73 \mathrm{~m}^{2}\right)$. By MRI LV mass was $166[81 ; 354] \mathrm{g}, \mathrm{LV}$

${ }^{1}$ Cardiology, University of Heidelberg, Heidelberg, Germany

Full list of author information is available at the end of the article ejection fraction $59[32 ; 72] \%$, MAPSE $8[2 ; 19] \mathrm{mm}$, and TAPSE $14[5 ; 23] \mathrm{mm})$. Thickness of atrial septum was $7[3 ; 10] \mathrm{mm}$. Late gadolinium enhancement was present in 26 patients (87\%). Mean sum of semiquantitative CE-CMR was 27.0 \pm 2.7 (maximal sum 48). By ${ }^{99 m}$ Technetium-DPD scintigraphy heart retention was $6.5[2.2 ; 9.5] \%$, heart-to-body retention was 8.0 $[3.5 ; 12.4] \%$.

LV ejection fraction and NT-proBNP correlated well with heart and heart-to-body retention. Furthermore, there was a significant correlation of median of LGE and MDRD with heart retention, but with not with heart-to-body retention. LV mass, MAPSE, TAPSE, thickness of interatrial septum as well as modified body mass index did not correlate with heart and heart-tobody retention.

In total, 6 patients died during median survival of 45 (13.6; 79.6) months. Multivariate analysis revealed median of MDRD, LV ejection fraction, and NTproBNP as independent predictors of survival, but not CE-CMR or scintigraphic heart retention.

\section{Conclusions}

This is the first report comparing different diagnostic tools for risk stratification of patients with TTR amyloidosis. This preliminary study demonstrates the potential impact of cardiac MRI and laboratory findings, but not ${ }^{99 \mathrm{~m}}$ Technetium-DPD scintigraphy for risk stratification of patients with TTR amyloidosis.

\section{Funding}

None.

\section{Author details}

${ }^{1}$ Cardiology, University of Heidelberg, Heidelberg, Germany. ${ }^{2}$ Nuclear Medicine, University of Heidelberg, Heidelberg, Germany. 
Published: 30 January 2013

doi:10.1186/1532-429X-15-S1-E112

Cite this article as: Scherer et al:: Non-invasive risk stratification of patients with TTR amyloidosis. Journal of Cardiovascular Magnetic Resonance 2013 15(Suppl 1):E112.

Submit your next manuscript to BioMed Central and take full advantage of:

- Convenient online submission

- Thorough peer review

- No space constraints or color figure charges

- Immediate publication on acceptance

- Inclusion in PubMed, CAS, Scopus and Google Scholar

- Research which is freely available for redistribution

Submit your manuscript at www.biomedcentral.com/submit

() Biomed Central 